\title{
II. Weltliteratur aus Hispanoamerika
}

Um besser zu verstehen, wie lateinamerikanische Literaturen zwischen 1959 und heute als Weltliteratur verhandelt und zirkuliert wurden, lohnt sich ein Blick in den literaturhistorischen Kontext des spanischsprachigen Amerika. ${ }^{1}$ Wie bildeten sich dort literarische Strukturen heraus und wie entstanden Poetiken, die vermehrt im Kontext von Weltliteratur rezipiert wurden? Wie verliefen solche Rezeptionsprozesse, insbesondere zwischen Lateinamerika und Europa? Die hispanoamerikanischen Literaturen sind seit der Zeit ihrer Entstehung bekanntlich in einem Spannungsfeld zwischen Emanzipation von und Anpassung an Europa wahrgenommen worden, wobei der Anpassungsdruck an Modeströmungen aus Europa bis zum Modernismo Ende des 19. Jahrhunderts als sehr viel stärker gilt als der emanzipatorische Akt. Seit dieser Phase entsteht eine Literatur, die verstärkt als unabhängig und genuin lateinamerikanisch rezipiert wurde. Schließlich wurde eine Reihe von Autor/innen um Gabriel García Márquez und Mario Vargas Llosa während des so genannten Boom in der zweiten Hälfte des 20. Jahrhunderts weltbekannt, und es gelang erstmals in der Geschichte der lateinamerikanischen Literaturen, überwältigende Erfolge am internationalen Buchmarkt zu erzielen. Welche Faktoren waren dafür verantwortlich, dass diese Werke eine weltliterarische Durchsetzungskraft erhielten, und in welchen literaturhistorischen Kontexten kann eine solche Rezeption lateinamerikanischer Literaturen als Weltliteratur verortet werden?

Eine kritische Perspektive im ersten Teil des Kapitels auf das so grundlegende wie - in manchen Fällen - problematische Rezeptionsmuster von Emanzipation und Anpassung an entscheidenden Kristallisationspunkten in der Geschichte der lateinamerikanischen Literaturen ermöglicht es, diese im Kontext der Weltliteraturdebatte neu zu bewerten. Im zweiten Teil des Kapitels sollen drei Beispiele herausgegriffen werden, die zeigen, inwiefern die Anschlussfähigkeit an bestimmte Diskurse oder Traditionen weltliterarische Rezeption bedingen kann, und die auch ein kritisches Verständnis dafür entstehen lassen, dass und warum andere denkbare Beispiele für Weltliteratur nicht als solche rezipiert worden sind.

Eng verwoben mit diesen Überlegungen ist die Tatsache, dass die Entscheidungen über die Zugehörigkeit zu einem Kanon von den Anfängen lateinamerikanischer Literaturen in der Kolonialzeit und zum Teil bis in die Gegenwart hinein in den verlegerischen Zentren Europas getroffen wurden, wobei seit Mitte des 20. Jahrhunderts auch die USA mit bedeutenden Verlagsstrukturen hinzukamen. Es muss natürlich immer mitreflektiert werden, wie sich solche

1 Vgl. dazu auch Müller (2019a).

Ә Open Access. ( 2020 Gesine Müller, published von De Gruyter. (G)BY-NC-ND Dieses Werk ist lizenziert unter der Creative Commons Attribution-NonCommercial-NoDerivatives 4.0 Lizenz. https://doi.org/10.1515/9783110692174-002 
Denominationszentren über die Jahrhunderte entwickelt haben: Wann und wo entstanden Strukturen, die eine Rezeption literarischer Werke aus Lateinamerika als Weltliteratur überhaupt hervorgebracht oder doch entscheidend mitbestimmt haben?

\section{II.1. Kristallisationspunkte im chronologischen Überblick}

\section{Kolonialzeit}

Mit Blick auf die neuspanische Autorin Sor Juana Inés de la Cruz (um 1648/ 51-1695) hat Vittoria Borsò (2015) eine sehr grundlegende Revision der klassischen Rezeption vorgenommen. Auch wenn sich ein explizites Konzept von Weltliteratur erst seit Goethe entwickelt hat, entspricht Sor Juana Inés de la Cruz im 17. Jahrhundert den wichtigsten Kriterien für Weltliteratur bereits nahezu idealtypisch, so Borsòs These, die sie anhand von fünf Gesichtspunkten auffächert: Erstens verbinde Sor Juana das Partikulare mit dem Universalen. In ihrem Werk werden insbesondere griechisch-lateinische Traditionen und spanische beziehungsweise europäische philosophische Ansätze $\mathrm{zu}$ den lokalen Kulturen in Lateinamerika in Beziehung gesetzt, vor allem zu der des Nahuatl. Zweitens zeigt Borsò, in welchem Maße Sor Juanas Werk als Wissensspeicher fungierte, indem die Autorin zeitgenössisches Wissen aus den verschiedensten Gebieten, unter anderen aus der Medizin, in ihr Denken und Arbeiten einfließen ließ. Drittens geht es ihr um einen politischen Anspruch, um den politischen Einsatz für Diversität, der in Sor Juanas klerikalem Umfeld höchst kritisch wahrgenommen wurde und bereits aufklärerischen Charakter hat. In ihrem Willen zur politischen Intervention steht Sor Juana am Beginn einer Reihe von Autor/innen aus Lateinamerika, die zu einem weltliterarischen Kanon gezählt werden können. Als viertes Kriterium für eine Zuordnung Sor Juanas zur Weltliteratur greift Borsò ein anthropologisches Moment auf und kommentiert die Art, wie Sor Juana zwischen Literatur und Leben verhandele. Es geht ihr um eine Reorganisation des Wissens, insbesondere bezüglich der sinnlichen Wahrnehmung des Menschen: Sor Juana habe den europäischen Sensualismus des 18. Jahrhunderts vorweggenommen. Fünftens habe sie neue Epistemologien hinsichtlich Philosophie und Theologie geprägt, was nach Borsò zu den wichtigsten Charakteristika weltliterarischer Werke gehört.

Borsò entwickelt ihre Thesen anhand verschiedener Texte und Textsorten bei Sor Juana, insbesondere aber an dem Text „El divino Narciso“ (1685), einem auto sacramental, das auf dem Intertext von Ovid zum Narciso-Thema basiert, den Calderón de la Barca wiederum in seiner Komödie Eco y Narciso weiterentwickelt hat. Bedeutsam ist dabei eine vielschichtige Übersetzungs- und Transformationsleistung Sor Juanas, mit der sie die theologischen Allegorismen des Genres in den 
neuspanischen Kontext überführt und dem allegorischen Diskurs eine neuartige materielle, territoriale und körperliche Konkretisierung einschreibt. Im Akt der Übersetzung von Symbolen und in der Inszenierung einer Diversität der Kulturen öffnet sich ein transformatorischer Raum, ein hybrider kultureller Raum des spanischen Territoriums in Lateinamerika, der in seiner Wirkungsmacht nicht zu unterschätzen ist. Neben Sor Juana sind hier auch der Peruaner Juan de Espinosa Medrano (um 1629-1688) sowie der Neuspanier Carlos de Sigüenza y Góngora (1645-1700) zu nennen. Mittels einer Hybridität, die verschiedene Wahrnehmungsweisen von Wirklichkeit und verschiedene Wissensmodi einbezieht, wird vom Textraum ausgehend die Autorität der kolonialen Ordnung infrage gestellt.

Ein Verständnis des kolonialen Barock in seiner transformatorischen Leistung ist entscheidend, um die Ursprünge eines Konzeptes von Weltliteratur in Lateinamerika auszumachen. In seinem Text „La curiosidad barroca“ (publiziert 1957 in La expresión americana) wendet sich José Lezama Lima in diesem Zusammenhang gegen das Bild der Assimilation und vertritt eine Auffassung, die nicht die hegemoniale Relation in den Blick nimmt, sondern eine freie Adaption und einen Austausch von Modellen. Er weist auch auf Beispiele aus dem Kontext klerikaler lateinamerikanischer Kunstpraxis hin, denen er eine größere künstlerische Freiheit und einen stärkeren Widerstand gegen die restriktive Welt der Gegenreformation attestiert, als sie in Spanien zur gleichen Zeit zu finden waren (Lezama Lima 1977 [1957]). Eine angemessene Wertschätzung und Einordnung der damit verbundenen künstlerischen Leistung erfolgt erst seit wenigen Jahrzehnten und steht teilweise noch aus.

\section{Modernismo}

Die Herausbildung einer eigenen, spezifisch lateinamerikanischen literarischen Tradition wird in der Literaturgeschichtsschreibung üblicherweise erst mit Vertretern des Modernismo assoziiert - oftmals etwas undifferenziert als These einer ersten emphatischen literarischen Unabhängigkeit Lateinamerikas von Europa. Am Beispiel des uruguayischen Essayisten und Autors José Enrique Rodó (1871-1917) lässt sich zeigen, wie auf avancierte inhaltliche wie formale Weise das europäische geistesgeschichtliche Kulturgut vielmehr kreativ anverwandelt (Ette 1994: 309) und weiterverarbeitet wird.

Die Parallelen zu einer Sor Juana Inés de la Cruz hinsichtlich dieser künstlerischen Anverwandlungsprozesse sind deutlich vorhanden, wenngleich der Kontext und die literarischen Mittel natürlich gänzlich andere sind. Rodó wurde anders als Sor Juana - als Weltliterat rezipiert, da er die so wichtige, neuartige Symbiose von Orientierung an abendländischem Kulturgut und autonomen Elementen leistet. Deutlich wird hier an einem frühen Beispiel, was für die Denomination lateinamerikanischer Autor/innen als Weltliteraten durch die 
verschiedenen Rezeptionsphasen hindurch entscheidend bleiben sollte: Die Anschlussfähigkeit an klassische Elemente der europäischen Tradition muss gewährleistet sein, um als Weltliteratur verhandelbar zu sein. Eine ähnliche Dynamik spielt auch bei anderen modernistas eine wichtige Rolle: Bei José Martí (1853-1895) wäre hier beispielsweise der Gedichtband Versos libres zu nennen, erstmals und noch unvollständig postum 1913 publiziert, der eine gänzlich neue, reimlose Verssprache einführt, während er gleichzeitig eine Vielzahl literarischer Stile verarbeitet, an eine barocke Rhetorik und insbesondere auch an romantische Themen und Modelle anknüpft. Eine neue, eigene und als lateinamerikanisch rezipierte Schreibweise wird bei Rubén Darío (1867-1916) mit dem berühmt gewordenen, 1888 erschienenen Gedichtband Azul publik und ist insofern in Europa anschlussfähig, als sie stark von der zeitgenössischen französischen Literatur beeinflusst ist. Neben einer Rezeption im Anschluss an französische Einflüsse (insbesondere Darío) und solchen aus der anglophonen Literatur (sehr deutlich bei Martí), lässt sich am Beispiel Rodó beziehungsweise des Modernismo noch eine weitere Entwicklung zeigen, die für die Rezeption modernistischer Autor/innen im Weltliteraturkontext entscheidend ist:

In der zweiten Hälfte des 19. Jahrhunderts entwickelte sich in Westeuropa eine relative Autonomie des literarischen Feldes, woraus sich entscheidende Folgen für die Etablierung von Denominationsprozessen von Literatur ergaben. Pierre Bourdieu hat bekanntlich herausgearbeitet, dass die Dreyfus-Affäre weit über Frankreich hinaus wirksam war und entscheidende Veränderungen mit sich brachte: So kommt der positive Begriff des Intellektuellen in Europa erst mit jener Dreyfus-Affäre auf, in der Emile Zola durch seine klare öffentliche und publizistische Stellungnahme zugunsten des zu Unrecht beschuldigten jüdischen Offiziers - so Bourdieu (1992: 186f.) - den autonomen Anspruch des literarischkulturellen Feldes zementierte. Das symbolische Kapital, das Wissenschaftler/innen oder Schriftsteller/innen innerhalb ihres eng begrenzten Teilfeldes erworben hatten, setzten diese nun bewusst ein, um zu Themen allgemein öffentlichen Interesses Stellung zu nehmen.

In Lateinamerika kann von einer ökonomischen Infrastruktur des literarischen Feldes zu jenem Zeitpunkt noch keine Rede sein. Allerdings lässt sich im Modernismo ein verhaltenes Echo der westeuropäischen Entwicklungen einer Autonomisierung vernehmen. Bereits bei José Enrique Rodó kam der literarischen Praxis eine für Lateinamerika neue Bedeutung zu. Er beschäftigte sich mit Fragen nach den Koordinaten einer potentiellen autochthonen, lateinamerikanischen Kultur, Identität und Literatur sowie ihrem Verhältnis zur europäischen wie nordamerikanischen Geistes- und Kulturgeschichte. In Rodós meistrezipiertem Werk Ariel, erstmals erschienen im Jahr 1900, proklamiert der Protagonist Próspero der Name stammt von der Hauptfigur aus Shakespeares The Tempest -, nah an 
den Lehren der französischen Philosophen Jean-Marie Guyau und Ernest Renan, ein Bildungsideal, das genuin universalistisch $\mathrm{zu}$ sein habe; eben einen prämodernen, präkulturellen, ganzheitlichen Zustand, der vor der für die Modernisierung so typischen „funktionalen Ausdifferenzierung gesellschaftlicher Teilsysteme“ (Lohmeier 2007: 9) noch möglich war. In seinem Amerikanismus löste sich Rodó nicht völlig von der europäischen Kultur.

Das Projekt einer geistigen Einheit Lateinamerikas als Vorstufe eines politischen Zusammenschlusses, wie Rodós Próspero es proklamiert, verfolgte auch Martí. Sehr aufschlussreich hinsichtlich einer sich langsam entwickelnden, auch strukturellen Unabhängigkeit des literarischen Feldes ist seine Positionierung im Zusammenhang publizistischen Informationsflusses: Während Martís frühe Zeitschriftenprojekte den noch immer dominanten Informationsfluss von Ost nach West anzeigen, hat Ottmar Ette anhand von Martís Schriften auch gezeigt, wie ein inneramerikanischer Informationsfluss in nord-südlicher Richtung etabliert wurde: „Seine [Martís] Chroniken und Essays dokumentieren in hervorragender Weise einen erstmals selbstgesteuerten Wissenstransfer, der an den Bedürfnissen der lateinamerikanischen Länder orientiert ist“ (Ette 1994: 308).

Doch wie entwickelte sich so etwas wie ein relativ autonomes Feld in Lateinamerika nach dem Modernismo weiter? Rein soziologische Faktoren sprechen gegen eine relative Autonomie des literarischen Feldes in Lateinamerika Ende des 19. Jahrhunderts. Der noch weit verbreitete Analphabetismus reduzierte nicht nur rein faktisch betrachtet die Leserpotentiale, sondern erschwerte auch die Konstituierung einer intellektuellen Elite. Der mexikanische Kulturtheoretiker Carlos Monsiváis hat die schwierigen Rezeptionsbedingungen $\mathrm{zu}$ jenem Zeitpunkt in Lateinamerika beschrieben (2000: 115): unter anderem ein prekäres Bibliothekswesen, ein sehr kleines Netzwerk von allein in den Hauptstädten angesiedelten Buchläden und wenige, teils instabile Verlagshäuser. Einziges Beispiel für eine erfolgreiche Rezeption sei der 1844 erschienene Bestseller María von Jorge Isaacs.

Die häufig vertretene These, man könne bereits mit dem Modernismo in Lateinamerika von einer Strömung sprechen, die sich nicht nur inhaltlich, sondern auch von den literaturbetrieblichen Voraussetzungen her parallel zu Europa entwickelte, lässt sich nicht halten. Die von Bourdieu für Frankreich in der zweiten Hälfte des 19. Jahrhunderts festgestellte Autonomie des literarischen Feldes, kann - trotz erster Ansätze hin zu einer Autonomisierung - nicht auf Lateinamerika übertragen werden. Die gesellschaftspolitischen Stellungnahmen blieben begrenzt, wohl in erster Linie deshalb, weil die Akteure institutionell noch fest in die Bereiche von Politik und Ökonomie eingebunden waren: So wie Rodó hatten fast alle Schriftsteller/innen bis in die 1960er Jahre Positionen im Regierungssystem inne. Solange sich in Lateinamerika Alphabetisierung und Demokratisierung noch auf eine kleine Minderheit beschränkten, war die Entwicklung einer eigenen 
Infrastruktur der literarischen Produktion noch nicht möglich. Nicola Miller folgert aus den nicht mit den Strukturen in Europa vergleichbaren Bedingungen, dass zu diesem Zeitpunkt nicht einmal der Begriff des Intellektuellen auf Lateinamerika übertragbar ist: „In Spanish America, by contrast, adoption of the word was symptomatic of the fact that the conditions for professional intellectual life were only incipient; in other words, the resonance of the idea was dependent on a nascent modernity“ (1999: 4). ${ }^{2}$

Starke Einschränkungen hinsichtlich der Strukturierung und Autonomie eines literarischen Feldes betreffen auch noch die nächste literarische Generation, die lateinamerikanischen Avantgarden der 1920er Jahre. Sie verfassten fast ausschließlich Lyrik, die einer größeren Breitenwirkung vorenthalten war, da der Leserkreis exklusiv blieb. So experimentell und progressiv die Werke auch sein mochten - man denke etwa an die hoch produktiven Autoren Vicente Huidobro (1893-1948) und César Vallejo (1892-1938) -, sie waren nicht in der Lage, sich eine vollwertige Infrastruktur literarischer Produktion zu schaffen.

\section{Jorge Luis Borges}

Auf dem Weg hin zu einer strukturellen Veränderung und Loslösung des literarischen Feldes vom politischen in Lateinamerika spielt Jorge Luis Borges (1899-1986) eine besondere Rolle, war er doch der erste lateinamerikanische Autor, der mit einer entsprechenden internationalen Resonanz zum Kanon der Weltliteratur gezählt wurde, wenngleich er mehr unter Autor/innen, Verleger/innen und Kritiker/innen erfolgreich war, als dass er zu Lebzeiten große Verkaufserfolge erzielt hätte. Sein Euvre nimmt in der lateinamerikanischen Literatur eine monolithische Position ein und es erweist sich als äußerst diffizil, Borges einer bestimmten literarischen Gruppe oder Strömung, einem bestimmten Genre oder einer epochalen Wende zuzuordnen. Sein Werk zeichnet sich durch eine außergewöhnliche Dichte an philosophischen, religiösen, künstlerischen Diskursen, Reflexionen und Kontexten aus sowie durch Texte, die zwischen literaturkritischen Essays, realistischer Prosa und Phantastik oszillieren. Diese universalistische Herangehensweise (Bell-Villada 1999: 295) ist es auch, die eine Zuordnung Borges' zu den Repräsentanten der Boom-Generation unmöglich macht, wollten deren wichtigste Vertreter doch eine genuin lateinamerikanische Literatur erschaffen, mit ganz eigenen inhärenten Funktionsmechanismen, Gattungen und Inhalten. Er kann auch kaum als rein modernistischer oder postmoderner Autor klassifiziert werden. Die Frage, weshalb Borges' literarisches Schaffen kanonisiert wurde und

2 Vgl. dazu auch Müller (2004: 74-78). Eine lesenswerte Studie über die Entstehung der Figur des Intellektuellen im Kontext moderner Ideologien hat jüngst Gonzalo Navajas (2019) vorgelegt. 
welche literarische Qualitäten seine Schriften besitzen, die diese zu weltliterarischem Rang erheben, ist sehr komplex und insbesondere in einer Studie von Alan Pauls (2004) hervorragend bearbeitet worden. Pauls betont die vielen Formen der Resonanz auf Borges' Werk sowie die Vielfältigkeit der charakteristischen literarischen Elemente bei Borges. Aspekte des Unverwechselbaren dieses Autors werden nicht nur in dessen literarischen Texten herausgearbeitet, sondern ebenso anhand von Interviews, Postkarten, Briefen, Radiobeiträgen und ähnlichen Dokumenten. Pauls sucht Borges auch in seiner Stimme, seiner Körperlichkeit und insbesondere auf einer Ebene, die er als zugleich intim und theatralisch, privat und öffentlich charakterisiert: „El Borges on stage“ (Pauls 2004: 8). Während Borges literarisch sicherlich eine Einzelstellung innehat, verweist diese Vorstellung eines „Borges on stage“ bereits auf die Inszenierung der Boom-Autoren in einem sich strukturell stark verändernden literarischen Feld.

Im Kontext der Weltliteraturfrage hoch interessant ist Borges' universalistisches, oft als weltliterarisch verhandeltes Konzept, das er in seinem bereits zitierten, 1955 veröffentlichten Essay „El escritor argentino y la tradición“ erläutert. Er greift darin zeitgenössische Positionen zu der Frage auf, wie eine argentinische oder auch lateinamerikanische Literatur auszusehen habe, und formuliert eine Poetologie jenseits nationalpoetischer Zuschreibungen. Borges kritisiert zunächst, dass die als argentinische Nationalliteratur gepriesene und proklamierte literatura gauchesca eigentlich keine Weiterführung der tatsächlichen argentinischen poesía popular, der Volksdichtung, sei. Die Imitation der volkstümlichen Sprache sowie die pseudo-mimetische Darstellung von imaginierten, argentinischen Stereotypen sei genau das Gegenteil der poesía popular. Diese reflektiere vielmehr größere (epistemologische, religiöse, philosophische) Weltzusammenhänge und bediene sich dabei einer allgemeingültigen Sprache sowie diverser topisch besetzter Bilder und Metaphoriken. Borges nennt hier Verse aus La urna von Enrique Banchs (1888-1968), in denen sich dieser des griechisch sowie germanisch aufgeladenen kulturgeschichtlichen Bildes der Nachtigall bedient, um eine „Poesie des Höheren“ zu erschaffen. So sei es ein Irrtum, dass sich die argentinische Dichtung ausschließlich in spezifisch argentinischen Charakteristiken manifestiere. Nicht nachvollziehbar ist für Borges die Idee, dass man einen Autor nationalspezifisch als französischen oder englischen Dichter bezeichne, da er in seinen Schriften immer auch über solche Zuschreibungen hinausgehende Themen behandele (Racine mit römischen beziehungsweise griechischen Sujets, Shakespeare mit dänischen). Positionen einer national-argentinischen Literatur lehnt er ab und zeigt, dass es sich dabei um relativ neue Auffassungen handelt, die sich literaturgeschichtlich nicht begründen lassen. Damit grenzt er sich auch ab von der an eugenische, darwinistische und rassistische Vererbungstheorien des 19. Jahrhunderts erinnernden nationalistischen Annahme, ein bestimmtes Schreiben ergebe sich aus der historischen 
Abstammung: Wenn Argentinier also ähnlich wie Spanier schrieben, so Borges, sei dies weniger ein Zeugnis einer ererbten Fähigkeit als eher ein Beweis für die universale intellektuelle Vielseitigkeit der Argentinier.

Die gegenläufige These, dass die Argentinier durch den Status als noch junge und erst kürzlich gegründete Nation (1816) keine Vergangenheit hätten, sich somit in der kulturgeschichtlichen Situation der Tabula rasa befänden und sich folglich besonders von Europa emanzipieren und distanzieren müssten, ist für Borges aber genauso wenig haltbar. Denn die sich in Europa ereignenden Geschichtsläufe des 20. Jahrhunderts, ob der Zweite Weltkrieg oder der Spanische Bürgerkrieg, als Konflikte höherer politischer, ideologischer Positionen, beträfen die Argentinier emotional genauso - als Nachfahren der Europäer wie auch als Weltbürger. Borges plädiert für eine Emanzipierung von sämtlichen die Kunst und das Denken determinierenden Modellen und fordert einen souveränen Umgang mit der europäischen Vergangenheit und Kulturgeschichte (vgl. Borges 1955).

Letztlich ist es wohl auch die wiederholte Forderung nach einer universalistischen Ausrichtung der argentinischen, südamerikanischen und lateinamerikanischen Literatur, die Borges für eine Reihe (nicht nur) lateinamerikanischer Autor/innen zum zentralen Referenzpunkt macht: Autor/innen, die eine intellektuelle Fremdbestimmung und Einengung ablehnen und dabei oftmals - wenn auch auf sehr unterschiedliche Weise - intertextuell arbeiten wie der Italiener Umberto Eco, der Chilene Roberto Bolaño ${ }^{3}$ oder die Mexikanerin Valeria Luiselli.

\section{Der Boom}

Nachdem mit Jorge Luis Borges der erste Weltliterat mit einer für diesen Kontext zukunftsweisenden Poetologie und einer breiten internationalen Wirkungsmacht benannt ist, gilt es, strukturelle Entwicklungen nachzuzeichnen, die den Weg für eine noch weitaus umfassendere Rezeption lateinamerikanischer Autor/innen ebneten. Zwischen den 1950er und den 1970er Jahren gibt es nach Nestor García Canclini (1989) in Lateinamerika entscheidende Entwicklungen, die auf einen strukturellen Wandel hinweisen: wirtschaftlicher Aufschwung, Städtewachstum, Erweiterung des Marktes der kulturellen Güter, Zunahme des Schul- und Universitätsbesuchs, Rückgang des Analphabetismus auf 10-15 \%. In Argentinien, Mexiko und Brasilien kommt es um $1940 \mathrm{zu}$ einem Aufschwung der Buchindustrie. Der peruanische Autor Mario Vargas Llosa registriert Mitte der 1960er Jahre, dass endlich in Lateinamerika ein günstigeres Klima für die Literatur entstehe. Buchclubs und Lesezirkel begännen sich auszuweiten und die Bourgeoisie

3 Vgl. zu Roberto Bolaños intertextuellem Werk und seiner Rezeption weltweit die Studie von Benjamin Loy (2019). 
habe entdeckt, dass Bücher wichtig und Schriftsteller mehr seien als harmlose Narren, dass sie eine Aufgabe zu erfüllen hätten (Vargas Llosa 1971 [1967]: 19). Martha Zapata Galindo zeigt am Beispiel von México en la Cultura der Zeitung Novedades, die dann von Siempre mit der Beilage La Cultura en México abgelöst wurde, wie in den 1950er Jahren die wichtigsten intellektuellen Gruppen in Mexiko in Verbindung mit Zeitschriften, Zeitungsbeilagen oder universitären Einrichtungen entstanden, in denen sie hohes Ansehen und kulturelle Macht akkumulierten. $\mathrm{Zu}$ diesem Zeitpunkt begannen Schriftsteller/innen und Intellektuelle auf Distanz zum offiziellen Nationalismus des mexikanischen Staates zu gehen. Eine wichtige Station auf dem Weg zu einem breiteren Zugang zu weltweit relevanten Denominationszentren, die über aus Lateinamerika kommende Weltliteratur entscheiden, bildet auch gerade in Mexiko die Gründung oder Expansion einiger Verlage wie Era, FCE, Joaquín Mortiz und UNAM, die sich gegenüber jüngeren Autor/ innen als sehr offen erwiesen (Zapata Galindo 2003: 103-105, s. Müller 2004: 78f.).

Dieser strukturelle Wandel in ganz Lateinamerika bereitete den Boden dafür, dass lateinamerikanische Autor/innen erstmalig in einer kontinentalen Breitenwirkung international wahrgenommen wurden. Dass eine Zugehörigkeit zum weltliterarischen Kanon und feldsoziologische Faktoren untrennbar miteinander verbunden sind, zeigt sich geradezu modellhaft bei den Romanautor/innen der 1960er Jahre, die häufig zum sogenannten Boom der lateinamerikanischen Literatur gezählt werden. Erstes sozioökonomisches Indiz für die erlangte - wenn auch immer nur relative - Autonomie war die institutionelle Unabhängigkeit etwa eines Gabriel García Márquez (und anderer Autor/innen seiner Generation) vom Regierungssystem, die in diesem Ausmaß erstmalig in Lateinamerika zutage tritt. Entscheidender jedoch war die ethische Unabhängigkeit, die jene Autor/innen mit ihrer Berufung auf das Volk gegenüber der politischen Klasse geltend machten und derentwegen sie sich zu Trägern von Universalwerten emporschwangen. Sie beanspruchten, die Bedürfnisse eines pueblo zu artikulieren, das sie sowohl durch kapitalistische Klasseninteressen wirtschaftlich unterdrückt als auch durch europäische Vorherrschaft kulturell gegängelt sahen. Ihren Stiftungsakt als Intellektuelle vollzogen sie, indem sie unter Berufung auf genuine Normen des literarischen Feldes in das politische Feld eingriffen. Die Unabhängigkeit gegenüber den staatlich-gesellschaftlichen Machtinstanzen und die damit einhergehende, implizite Eigenständigkeit des literarischen Feldes war eine entscheidende Voraussetzung, um Zugang zu den verlegerischen Zentren in Europa und den USA zu bekommen (Müller 2004: 79, 275).

Der Boom der lateinamerikanischen Literatur der 1960er Jahre mit den schnell zu Bestsellern avancierten Romanen von Gabriel García Márquez, Mario Vargas Llosa, Carlos Fuentes, Julio Cortázar und anderen hängt neben den soziologischen auch mit anderen - für weltliterarische Kanonisierungsprozesse sehr 
relevanten - Faktoren zusammen. Julio Cortázar brachte den kleinsten gemeinsamen Nenner der Boom-Romane so auf den Punkt: „Qué más es el boom, si no la más extraordinaria toma de conciencia del pueblo latinoamericano de su propia identidad?““ (zit. nach Rama 1982: 244). Aus innerliterarischer Perspektive stehen ganz klar Identitätsfragen im Zentrum der literarischen Produktion der BoomGeneration. Der Schwerpunkt liegt hier wohlgemerkt auf dem Prozess der Bewusstwerdung, der Identitätssuche, sei es nun im Rückgriff auf präkolumbianische Mythen, zyklische Zeitstrukturen oder experimentelle Erzählverfahren.

Eine entscheidende Rolle spielten dabei die politischen und sozialen Befreiungsbewegungen, die auf dem Subkontinent immer drängender wurden. Die Kubanische Revolution etwa kann als Auftakt angesehen werden; und das, obwohl der Name Boom sicherlich die rein wirtschaftlichen Erfolge meint, die vor allem dem Haus Seix Barral in Barcelona zu verdanken sind, das die lateinamerikanischen Autoren auf den Markt brachte. Der Glaube an die Kubanische Revolution verband alle Boom-Autoren: Sie wollten dem durch Analphabetismus und Armut zum Schweigen verdammten Volk eine Stimme verleihen, durchaus in Anlehnung an Sartres Konzept vom engagierten Intellektuellen. So war es zumindest bis 1971 - als Herberto Padilla wegen eines kritischen Gedichtbandes vom Castro-Regime verhaftet wurde und bald danach in einem Schauprozess sein öffentliches Schuldbekenntnis ablegte. Bei vielen marxistischen oder marxistisch inspirierten Intellektuellen Lateinamerikas ließ das die Kuba-Utopie ins Wanken geraten. Mit ihrem Protestbrief an Castro und einer Unterschriftenaktion in Le Monde distanzierten sie sich von dem kommunistischen Regime.

\section{Boom-Erfolge und Exklusionsmechanismen}

Sowohl dem Identitäts- als auch dem Lateinamerikabegriff, die den Boom-Erfolgen zugrunde liegen, sind Exklusionsmechanismen inhärent, die kritisch hinterfragt und teilweise noch beforscht werden müssen. Zentral sind Gender- und Genrefragen, etwa die Frage, warum sich selbst im erweiterten Kreis der dem Boom zugerechneten Autoren keine Frau befindet oder warum er sich allein auf die Erzählliteratur auswirkte. Grundsätzlich ist nicht $\mathrm{zu}$ rechtfertigen, dass die brasilianische Literatur in dieser weltweiten und massiven Zirkulation lateinamerikanischer Literaturen eine derart marginale Rolle spielt. ${ }^{4}$ Wie ist es darüber hinaus zu bewerten, dass alle Vertreter des Boom nicht nur männlich und

4 Vgl. zu den Aspekten von Marginalisierung brasilianischer Autor/innen bzw. von Frauen die Studien von Leonie Meyer-Krentler zu Clarice Lispector: Clarice Lispectors doppelte Isolation (in Vorbereitung) zu Übersetzungs- und Rezeptionsdynamiken im Kontext der aktuellen Debatte um Weltliteratur sowie in der Reihe „Leben in Bildern“ des deutschen Kunstverlags der Band Clarice Lispector (2019). 
spanischsprachig waren, sondern zugleich Angehörige der weißen Mittel- und Oberschichten des Subkontinents? Welche Gründe gab es für die Tatsache, dass herausragende Autoren wie Juan Carlos Onetti, Guillermo Cabrera Infante, Antonio Di Benedetto oder Salvador Elizondo als Zeitgenossen der Boom-Autoren nicht Teil des globalen Erfolgs waren, wie er dem Netzwerk um García Márquez, Fuentes oder Vargas Llosa zuteilwurde? Die Analyse dieser implizit sich vollziehenden Exklusionsmechanismen berührt den fundamentalen Aspekt der Übersetzung als conditio sine qua non von Weltliteratur (vgl. Venuti 2012). Wenn für David Damrosch bekanntlich ein Hauptkriterium von Weltliteratur „writing that gains in translation“ (2003: 288) lautet, dann stellt sich bezüglich besagter Ausschließungsverfahren nicht zuletzt die Frage, welche Rolle das komplexe Feld der Übersetzung innerhalb globaler Zirkulationsprozesse von Literatur einnimmt. Emily Apter hat darauf hingewiesen, dass dabei gerade Texte problematisch sind, welche durch Elemente der Unübersetzbarkeit eine geringere Anschlussfähigkeit an verlegerische Publikationsstrategien aufzuweisen scheinen (Apter 2013). Allerdings hat das Interesse an theoretischen Fragen der Unübersetzbarkeit eine Zeitlang den Blick verstellt für konkrete politics of translation, etwa was die Übersetzungsförderung angeht oder die Rolle einzelner Übersetzer. ${ }^{5}$

\section{Nach dem Boom}

Für das Spätwerk der zu Stars avancierten Schriftsteller aus Lateinamerika kann man bereits ab den 1970er Jahren, spätestens aber ab 1989 einen Abschied von den großen identitätsstiftenden Entwürfen konstatieren. Dies lässt sich auf die Formel bringen: vom pueblo zum público, also eine Verlagerung vom (lateinamerikanischen) Volk, für das gesprochen werden sollte, hin zum Publikum, in erster Linie $\mathrm{zu}$ einem europäischen und nordamerikanischen Publikum, an dessen Geschmack und Erwartungshaltung man sich immer mehr orientierte. Dafür steht der Rückzug in die betonte Lesbarkeit, narrative Entwürfe, die sich nicht nur in den Erzählstrategien, sondern auch in der Wahl des Stoffs eher an europäischen oder nordamerikanischen Mustern orientieren und schließlich auch die literarische Inszenierung des eigenen Frühwerks, vordergründig sicherlich eine Distanznahme, doch zugleich ein ständiges Spielen mit (und Erinnern an) die eigenen Erfolge.

Dezidierter noch als ihre literarischen Väter erklärten jüngere Autor/innen den Themen der 1960er Jahre ab Beginn der 1990er eine Absage. So parodierten die Gruppen Crack mit Jorge Volpi oder auch McOndo mit Alberto Fuguet in ihren Manifesten das spezifisch Lateinamerikanische und wandten sich häufig in ihren

5 Eine Ausnahme bildet hier etwa der Band von Roig-Sanz/Meylaerts (2018). 
Werken ostentativ ab von lateinamerikanischen Themen. Ob das mit einem Rückgang der Erfolge in der spanischen und lateinamerikanischen Verlagsindustrie zusammenhängt, sei dahingestellt (vgl. dazu auch Müller 2004, 257-261).

Nach dem Boom, mit seinen großen Verkaufserfolgen in Europa und den USA, ist vor allem einem lateinamerikanischen Autor des 20. Jahrhunderts von Seiten der Literaturkritik, der international agierenden Verlage und auch der Literaturwissenschaft noch einmal der Rang von Weltliteratur zugesprochen worden: dem Chilenen Roberto Bolaño (1953-2003), der in seiner Wirkungsmacht eine ähnlich monolithische Einzelstellung einnimmt wie Borges für seine Zeit. Nach einer Jugend in Mexiko lebte Bolaño ab 1977 in Spanien. Unter Schriftsteller/innen und Kritiker/innen erfuhr er nach seinem Tod 2003 und insbesondere nach dem großen Erfolg seines posthum erschienenen Romans 2666 in den USA eine einzigartige Rezeption, während er am Markt zunächst keinen übermäßigen Erfolg erzielte. In seiner Poetologie gibt sich Bolaño wie Borges eher wenig lateinamerikanisch. Ihm ist ein mehr universalistisches, literarischen Bezügen und Einflüssen aus verschiedensten Zeiten und Traditionen nachgehendes Literaturverständnis zu eigen, das auf Borges’ Erzählungen genauso verweist wie auf Baudelaire oder Mallarmé. Seine Themen sind dabei sehr stark in der politischen und sozialen Gegenwart Lateinamerikas verankert, insbesondere, was Erfahrungen von Exil und Gewalt angeht. Ein Verständnis dafür zu wecken, dass diese Themen nicht allein lateinamerikanisch sind, obwohl sie in ihren lateinamerikanischen Kontexten erzählt werden, etwa dem Kontext der unzähligen Frauenmorde im mexikanischen Grenzgebiet zu den USA in den 1990er Jahren (2666, 2004), ist eine der herausragenden Leistungen des literarischen Werkes von Roberto Bolaño.

\section{II.2. Rezeptionsmuster: Varianten weltliterarischer Anschlussfähigkeit}

Mit den folgenden Überlegungen sollen drei Varianten der Rezeption vorgestellt werden, die zeigen, wie über die Anschlussfähigkeit literarischer Werke an etablierte Diskurse und Traditionen sowie programmatische (Selbst-)Positionierungen von Autor/innen weltliterarische Durchsetzungskraft entstehen kann: Erstens Elena Poniatowska, deren Werk sich durch eine besondere Anschlussfähigkeit an linksgerichtete politische Diskurse in den 1970er und 1980er Jahren auszeichnet, während hier gleichzeitig die Frage nach Exklusionsphänomenen hineinspielt. ${ }^{6}$

$6 \mathrm{Zu}$ Exklusionsprozessen und mexikanischen Autorinnen vgl. das Kapitel „The Idea of the Mexican Woman Writer“, in: Sánchez Prado (2018c: 139-182). 
Zweitens Jorge Volpi, der in seiner programmatischen Abkehr von einer Erwartungshaltung an spezifisch lateinamerikanisches Schreiben zu einem weltweiten Erfolg gelangte und eine hohe Anschlussfähigkeit an Klassiker der westlichen (Wissenschafts-)Geschichte aufweist. Drittens Juan Gabriel Vásquez als Beispiel für eine spezifische Anschlussfähigkeit an in Europa etablierte Traditionen und die Tendenz, sich als Autor/in von spezifisch lateinamerikanischen Identitäten $\mathrm{zu}$ lösen und das eigene Werk explizit weltliterarisch zu positionieren.

\section{Elena Poniatowska}

Das Werk der mexikanischen Autorin Elena Poniatowska ( ${ }^{\star}$ Paris 1932) ist im Kontext des Boom vergleichsweise wenig zirkuliert worden. Immer wieder ist darauf verwiesen worden, wie exklusiv die Erfolgsautoren des Boom männlich, weiß und Angehörige der oberen Mittelschichten waren. Pierre Bourdieu schreibt über soziale, männliche Dominanz befördernde Praktiken: „[...] quelle que soit leur position dans l'espace social, les femmes ont en commun d'être séparées des hommes par un coefficient symbolique négatif qui [...] affecte négativement tout ce qu'elles sont et ce quelles font, et qui est en principe d'un ensemble systématique de différences homologues“ (Bourdieu 1998: 100 [Hervorh. im Orig.], s. auch Sánchez Prado 2018c : 140f.). Dies ist sicher auch zutreffend für das literarische Feld Lateinamerikas in den 1970er und 1980er Jahren, eine Phase, die für die Rezeption Poniatowskas entscheidend war. Gleichzeitig muss auch der Blick darauf gelenkt werden, dass Poniatowska vor diesem Hintergrund in manchen Kontexten geradezu zur weiblichen Vorzeigeautorin wurde, die gleichzeitig anschlussfähig war an Positionen linker politischer Diskurse in Europa. Poniatowska schrieb dezidiert politisch motiviert am Kanon der novela testimonial mit. Ihr Werk bewegt sich zwischen kritischem Journalismus und einer sehr spezifischen literarischen Schreibweise, die Interviews, Fakten und Tatsachenberichte mit fiktionalen Komponenten vermengt. Häufig geht es darum, marginalisierten gesellschaftlichen Gruppen eine Stimme zu verleihen. Die Verbreitung ihrer Werke wurde vom Interesse US-amerikanischer (überwiegend weiblicher) Literaturwissenschaftler/innen in den 1970er und 1980er Jahren entscheidend begünstigt (Schuessler 2007: 243). Insbesondere die beiden Titel Hasta no verte, Jesús mío (1969) und La noche de Tlatelolco (1971) erfuhren eine intensive und äußerst positive Rezeption. La noche de Tlatelolco, eine auf Interviews beruhende, collagenhafte Chronik der blutigen Ereignisse vom 2. Oktober 1968, erschien in englischer Übersetzung erstmals 1975 bei Viking Press in New York (Massacre in Mexico; Übersetzung von Helen R. Lane) und wird zu den Klassikern der lateinamerikanischen testimonio-Literatur gezählt. Cynthia Steele etwa bezeichnet in ihrer Studie Politics, Gender, and the Mexican Novel, 1968-1988: Beyond the Pyramid von 1992 Poniatowska - neben Carlos Monsiváis - als „responsible for converting 
the testimonial novel and the social and political chronicle into the quintessential narrative genre of the seventies and eighties“ (Steele 1992: 11, zit. nach Schuessler 2007: 247). Weiter betont Steele Poniatowskas Engagement für die

powerless, marginalized, and oppositional members of society who lack access to self-representation in print and the media: the handicapped, AIDS victims, earthquake victims, women artists and writers of the past, political performers, political prisoners, tradeunion organizers, opposition leaders, servants, garment workers, Indian women. (Steele 1992: 11f., zit. nach Schuessler 2007: 247)

Hier zeigt sich einer der beiden bedeutenden Stränge in der internationalen akademischen Rezeption Poniatowskas, der die linksgerichtete gesellschaftskritische Ausrichtung ihrer Schriften und die literarische Dokumentation marginalisierter Lebenswirklichkeiten in den Fokus nimmt und der auch in jüngeren Publikationen prominent vertreten ist:

Las crónicas de Elena Poniatowska son antídotos literarios y efectivos a las acciones del sistema político. Frente al olvido oficial y temporal, la memoria y la huella histórica; frente a la falsedad y tergiversación de los hechos, la autenticidad y la fidelidad; frente a la superficialidad, lo necesario y auténtico; frente al escueto registro de hechos, el tratamiento creativo y poético. (Poot Herrera 2017: 21)

Daneben sind im Laufe der Jahre zahlreiche akademische Arbeiten entstanden, die Poniatowskas Werk durch die Linse des Paradigmas vom ,weiblichen Schreiben' analysieren, häufig im Kontext weiterer mexikanischer (oder auch lateinamerikanischer) Autorinnen wie Elena Garro oder Rosario Castellanos. Allgemein lässt sich sagen, dass die Wertschätzung ihres Werkes von Seiten der Literaturwissenschaft und Literaturkritik ausgeprägt ist; Poniatowska wird oft im gleichen Atemzug mit Octavio Paz, Carlos Fuentes oder Gabriel García Márquez genannt. Sowohl das journalistische als auch das literarische Werk der Autorin sind seit Beginn der 1970er Jahre Gegenstand einer konstant wachsenden Zahl akademischer Veröffentlichungen: Bis 2007 entstanden allein in den USA 24 Dissertationen zu ihren Werken. Zum Vergleich: Zu Carlos Fuentes wurden im gleichen Zeitraum 70, zu Octavio Paz 53 und zu Rosario Castellanos 33 Dissertationen verfasst. Außerdem war Poniatowska Gastprofessorin an verschiedenen US-Universitäten und erhielt eine kaum noch zu überblickende Zahl an Ehrendoktorwürden (Schuessler 2007: 254). Poniatowskas literarischer Ruhm wurde von einer ganzen Reihe literarischer Auszeichnungen weiter gefestigt und in die Öffentlichkeit getragen, ${ }^{7}$ die

7 Unter anderem wurde sie 1978 als erste Frau mit dem mexikanischen Premio Nacional de Periodismo geehrt, 2002 mit dem Premio Nacional de Ciencias y Artes und 2004 mit dem 
2013 in der Verleihung des Premio Cervantes gipfelte, des renommiertesten Preises für spanischsprachige Literatur - eine Ehre, die vor ihr nur drei Frauen zuteil geworden war (vgl. Benmiloud/Lara-Alengrin 2014: 18). Seit 2008 gibt es sogar einen Elena-Poniatowska-Literaturpreis für spanischsprachige Literatur, der jährlich anlässlich der Buchmesse in Mexiko-Stadt verliehen wird.

Dass ihre Strahlkraft weit über die Grenzen Mexikos, der USA und der spanischsprachigen Welt hinausreicht, zeigt etwa der chinesische Preis für den besten ausländischen Roman, den sie im Jahr 2002 für La piel del cielo gewann. ${ }^{8}$ Poniatowska gehört in China zu den bekanntesten mexikanischen Autor/innen, wie folgendes Zitat über Guillermo Pulido Gonzalez, Leiter des Instituts für Mexikostudien an der Beijing Foreign Studies University, zeigt: „When Guillermo Pulido Gonzalez first worked in China from 2008 to 2010, he was amazed that the Chinese people he encountered had been exposed to such Mexican writers as Carlos Fuentes, Elena Poniatowska and Octavio Paz through Chinese translations“ (Zhou 2015). Dies mag nicht allzu sehr überraschen, da linksgerichtete Literatur mit testimonio-Charakter in China zu diesem Zeitpunkt durchaus eine besonders dankbare und intensive Rezeption erfuhr. ${ }^{9}$

Betrachtet man nun die internationale Zirkulation von Poniatowskas Büchern genauer, so stellt man fest, dass sie über die Jahrzehnte hinweg kontinuierlich in viele verschiedene Sprachen übersetzt wurden, neben dem Englischen etwa ins Polnische, Französische, Dänische, Niederländische, Deutsche, Russische, Japanische, Italienische (vgl. Schuessler 2007: 258) oder eben auch Chinesische. Auffallend ist dabei, dass in den einzelnen Ländern jeweils verschiedene Werke für die Übersetzung ausgesucht wurden. Der Roman Dos veces única etwa, 2016 bei

ehrwürdigen Journalismus-Preis Maria Moors Cabot der Columbia-Universität. Die Auszeichnung mit dem Premio Alfaguara (2001 für La piel del cielo) erhöhte Poniatowskas Bekanntheitsgrad in der gesamten spanischsprachigen Welt (Schuessler 2007: 243). Ihr wurden auch renommierte internationale Literaturpreise verliehen, wie der Premio Internacional de Novela Rómulo Gallegos (2007 für El tren pasa primero), der Premio Biblioteca Breve (2011 für Leonora) und natürlich der Premio Cervantes (2013). 2006 erhielt sie als erste Mexikanerin den Preis für das Lebenswerk der International Women's Media Foundation in Anerkennung ihres Modellcharakters für zahlreiche junge Journalistinnen und ihrer Verdienste durch ihre wöchentliche Literaturwerkstatt, in der einige der vielversprechendsten weiblichen Literaturtalente Mexikos ausgebildet werden (vgl. Geddis 2007; Schuessler 2007: 256). Den Premio Villaurrutia, der Poniatwoska für La noche de Tlatelolco zugesprochen wurde, lehnte sie ab, da sie sich fragte: „¿quién iba a premiar los muertos?“ (Benmiloud/Lara-Alengrin 2014: 17).

8 Vgl. http://www.china.org.cn/english/culture/51680.htm.

9 Vgl. hierzu die Dissertationsschrift von Yehua Chen (im Druck) zu Übersetzung und Zirkulation lateinamerikanischer Literaturen in China, in der sie u. a. die politischen Dimensionen der Rezeption dieser Literaturen im 20. und 21. Jahrhundert während verschiedener Phasen der Entwicklung des chinesischen Verlagssektors in den Blick nimmt. 
Seix Barral erschienen, wurde noch im selben Jahr in Polen publiziert, aber sonst in keine weitere Sprache übersetzt. Die einzige chinesische Übersetzung wiederum ist ein Werk, das darüber hinaus nur ins Englische übersetzt wurde (und zwar erst ein Jahr nach dem Erscheinen der chinesischen Ausgabe): La piel del cielo, ausgezeichnet mit dem Premio Alfaguara 2001. Offenbar gab es kein verlegerisches Rezeptionsmuster, das eine stärkere internationale Durchsetzungskraft hätte entfalten und Poniatowska zu einer breiteren Rezeption und auch hinsichtlich der Verkaufszahlen zu einem Erfolg hätte verhelfen können.

In einem Interview darauf angesprochen, warum etwa ihr Werk Hasta no verte, Jesús mío, das nur zwei Jahre nach Gabriel García Márquez' Cien años de soledad erschienen war, nicht annähernd die gleiche internationale Resonanz erfuhr, führt Poniatowska als Grund zum einen die Tatsache an, dass sie als weibliche Autorin im literarischen Feld einen weitaus schwereren Stand gehabt habe als ihre männlichen Kollegen, zum anderen die ans Journalistische grenzende Form der Testimonialliteratur (Pino-Ojeda 1998: 145). Sicherlich spielen hier Fragen des literarischen Genres hinein; die Melange von reportageartigen und literarischen Elementen und der collagenhafte Stil Poniatowskas passten offenbar nicht recht in die Marketing-Kategorien der internationalen Verlage. Eine offene Frage bleibt etwa, warum La noche de Tlatelolco (1971), das stets zu den wichtigsten Werken der Autorin gezählt wird und ihren Ruhm mitbegründet hat, lange Zeit außer ins Englische (1975) offenbar in keine weitere Sprache übersetzt wurde. Besonders augenfällig ist diese Lücke auf dem deutschen Buchmarkt - ihren verlagspolitischen Hintergründen wird in Kap. III.2.8 intensiver nachgegangen.

Mit Blick auf jüngere internationale Rezeptionstendenzen lassen sich in den letzten Jahren zaghafte neue Entwicklungen feststellen. Poniatowskas erster Roman etwa, Lilus Kikus, 1954 in Mexiko erstpubliziert, begann erst ein halbes Jahrhundert nach seinem Erscheinen international zu zirkulieren: 2005 wurde er ins Französische und Englische und 2009 ins Italienische übersetzt. Die späte Verbreitung des Romans führt der US-amerikanische Verleger Poniatowskas auf drei Gründe zurück: Zum einen wurde der Roman zum Zeitpunkt seiner Veröffentlichung 1954 als Kinderbuch gelabelt. Zum anderen war die Autorin eine unbekannte Frau. Und schließlich fanden die feministischen Züge des Romans zum Zeitpunkt seiner Veröffentlichung keinen Anklang bei der Leserschaft, während genau dies im 21. Jahrhundert gewürdigt wird. ${ }^{10}$ In Polen ist aktuell eine intensive verlegerische Beschäftigung mit Poniatowskas Schriften festzustellen, was mit der Würdigung mit dem Premio Cervantes 2013 sowie mit ihrer polnischen

10 Nachzulesen auf der Internetseite der University of New Mexico Press: https://unmpress.com/ books/lilus-kikus-and-other-stories-elena-poniatowska/9780826335821. 
Abstammung zusammenhängen kann: Zwei der drei polnischen Übersetzungen wurden 2016 und 2017 publiziert. Im April 2017 würdigte Marcin Żurek Poniatowska mit einem ausführlichen Artikel zu ihrem Leben und Werk, in dem er auch ankündigte, aktuell sei eine Übersetzung von Juan Soriano, niño de mil años aus seiner Feder in Arbeit (Żurek 2017). Das so wichtige La noche de Tlatelolco ist seit 2014 dank des kleinen Toulouser Kollektiv-Verlags CMDE auch in französischer Sprache zugänglich, unter dem Titel La Nuit de Tlatelolco. Histoire orale d'un massacre d'État. All dies vermittelt den Eindruck, als werde Poniatowskas Werk nun langsam eine breitere internationale Rezeption zuteil.

\section{Jorge Volpi}

Jorge Volpi ( ${ }^{\star} 1968$ in Mexiko-Stadt) ist bekanntlich der Kopf der sich Mitte der 1990er Jahre mit einem eigenen Manifest etablierenden literarischen Strömung El Crack. Zentrales Anliegen literarischer Gruppen wie Crack oder auch McOndo ist eine Absage an die Diskurse des Magischen Realismus. Das heißt, die Erwartung eines spezifisch lateinamerikanischen Schreibens für Autor/innen, die ursprünglich aus Lateinamerika kommen, hat sich - zumindest in lateinamerikanistischen Kreisen - spätestens seit diesem Zeitpunkt endgültig überlebt. Diese paradigmatische Positionierung, die sich in der zweiten Hälfte der 1990er Jahre teilweise in Manifesten niederschlug, etablierte sich wenig später zum Kanonwissen lateinamerikanischer Literaturgeschichten. Für die Frage danach, wie Weltliteratur überhaupt gemacht wird, ist daher relevant, welche neuen, weltliterarisch rezipierbaren Muster dieser Paradigmenwechsel hervorbringt. Entlang welcher Brüche und Verwerfungen verläuft die literarische Neuorientierung in Lateinamerika selbst und welche Rezeptionsfilter werden dadurch international gefördert?

Jorge Volpis internationaler Durchbruch gelang mit dem Roman En busca de Klingsor, der 1999 erschien und, grob gesprochen, vom Atombombenprojekt des NS-Regimes handelt. Volpi hatte zuvor in Mexiko bereits fünf Romane veröffentlicht: A pesar del oscuro silencio (1993) über den mexikanischen Dichter Jorge Cuesta, Días de ira (1994), den politischen Roman La paz de los sepulcros (1995), sowie El temperamento melancólico (1996) und Sanar tu piel amarga (1997). En busca de Klingsor war aber der erste, der außerhalb Mexikos erschien: In Spanien von Seix Barral publiziert, veränderte dieser Roman, wie bei so vielen lateinamerikanischen Autor/innen, Volpis Karriere als Schriftsteller. Er wurde in 34 Sprachen übersetzt und in mehr als vierzig Ländern verkauft. ${ }^{11}$

11 En busca de Klingsor zirkulierte zunächst in Europa und den Vereinigten Staaten, bevor der Roman auch auf dem hispanoamerikanischen Markt rezipiert wurde (López de Abiada/ Leuenberger 2004: 358). 1999, im Jahr der Veröffentlichung in Spanien, waren die Übersetzungsrechte schon an Verlage in den USA (Scribners), dem Vereinigten Königreich (Fourth State), 
Carlos Fuentes beschrieb En busca de Klingsor als „moral fable of our time“ (zit. nach Regalado López 2013: 101) und Guillermo Cabrera Infante sprach von einer „novela alemana escrita en español“ (zit. nach López de Abiada/ Leuenberger 2004: 359), was in den zeitgeschichtlichen Bezügen zu Deutschland, aber auch in den impliziten Verbindungen zu Thomas Manns Doktor Faustus begründet sein dürfte. Für das Genre, das nur schwer festzulegen ist, findet Cabrera Infante die Bezeichnung „ciencia-fusión“ (zit. nach ebd.), da das Werk Wissenschaft mit Geschichte, Politik und Literatur vermengt. Die Gattungsmischung, die weit über einen klassischen Roman hinausreicht, ist immer wieder Thema, so wird Volpis Werk als „una suerte de compendio razonado“ oder „una especie de divulgativa enciclopedia de la ciencia moderna“ (Solano 1999: 13, zit. nach Hunziker 2005: 57) bezeichnet. Der Roman sei

una de las novelas más complejas y arrebatadoras de los últimos tiempos escritas en castellano: un relato documentadísimo que es, a su vez, ficción y testimonio, novela de suspense o espionaje, crónica histórica y científica, retablo de fascinantes y contradictorios personajes, historia de amores y obsesiones fatales y, finalmente, una novela de ideas. (Dés 1999: 28, zit. nach Hunziker 2005: 58)

In einem Interview mit Volpi aus dem Jahr 2000 ordnet Mihály Dés, der Herausgeber von Lateral, den Welterfolg von En busca des Klingsor folgendermaßen ein: „la recepción de la novela y las múltiples contrataciones extranjeras son muestras de un reconocimiento que no se ha visto desde las novelas del boom“ (Dés 2000: 28f., zit. nach Hunziker 2005: 59).

Wie bereits erwähnt, sind weder die Charaktere von En busca de Klingsor noch die Szenarien lateinamerikanischer Natur - entsprechend dem Credo von Crack -, was eine Debatte zwischen den Vertreter/innen des Lokalismus einerseits und denen des Kosmopolitismus andererseits entfachte. Es wurden Stimmen laut, die den Roman als Verrat der mexikanischen Tradition empfanden, so wird zum Beispiel der Literaturkritiker und -wissenschaftler José Felipe Coria in einem Artikel in El País vom 19. April 2000 zitiert mit den Worten:

Deutschland (Klett-Cotta), Frankreich (Plon), Italien (Mondadori) sowie in den Niederlanden, Brasilien, Portugal und Israel verkauft worden - Rechte im Gesamtwert von einer halben Million US-Dollar (Ángel Villena 1999). Nur anderthalb Jahre nach seinem Erscheinen kursierte in Spanien bereits die fünfte und in Mexiko sogar die siebte Neuauflage (Hunziker 2005: 59). Im Jahr 2004 gab Volpi selbst an, die spanischsprachige Ausgabe habe sich bereits 70.000 Mal verkauft (E-Mail vom 5. August 2004, zit. nach ebd.). 
Ya no notamos que sea un novelista mexicano que le está hablando al público mexicano, muchos de los temas son como una nostalgia del ser europeo. Su forma de concebir la novela no es como una experiencia personal, sino como una opción sin pasado. Les importa más la técnica literaria que llegar a impactar o tratar de encontrar una voz personal. Lo grave es la impersonalidad con que se puede llegar a escribir. Su obra pudo haber sido creada en Europa, Suramérica o cualquier parte. (Ortega Ávila 2000)

Der Vorwurf, der im Raum steht, bezieht sich auf die kosmopolitische Ausrichtung eines mexikanischen Autors. Er trifft die Crack-Autor/innen im Allgemeinen, aber im Speziellen auch den Roman, mit dem Volpi der internationale Durchbruch gelang:

the crack novels are a heteroclite combination of unequal stories (some of them are disastrous) whose starting flag is a false cosmopolitanism, a literature written by Latin-Americans who had decided to abandon, as if it was too radical, the old national subjects and introduce themselves as contemporary. (Domínguez Michael 2004: 48, zit. nach Alvarado Ruiz 2017: 41)

Andere Lesarten hingegen sehen Volpi vielmehr in der Tradition von Jorge Luis Borges’ Kurzgeschichten wie „Deutsches Requiem“ oder Romanen wie José Emilio Pachecos Morirás lejos und Roberto Bolaños La Literatura Nazi en América. ${ }^{12}$ Zudem begreift Volpi Literatur als Ausgangspunkt für Kritik, lehnt absolute Dogmen ab und auch der konstruktive Dialog mit Kritiker/innen und Literaturwissenschaftler/innen aus Spanien, Lateinamerika und den Vereinigten Staaten entpuppt sich als gewinnbringend für seine Werke, die stets stereotypische Annahmen über das Dasein als lateinamerikanischer Autor infrage stellen (vgl. etwa Regalado López 2013: 101-104).

Ganz deutlich zeigen sich im lateinamerikanischen Kontext divergierende Lektüremuster, die die neue literarische Ausrichtung von Volpis Welterfolg im Speziellen und der Crack-Literatur im Allgemeinen mal als falschen Kosmopolitismus kritisieren und mal als zeitgemäße Transterritorialität feiern und die in ihrer Widersprüchlichkeit den Brüchen und Reibungen entsprechen, mit denen ein Paradigmenwechsel stets einhergeht. Die Rezeption dieser ,neuen“ lateinamerikanischen Literatur durch die Literaturkritik außerhalb Lateinamerikas bewegt sich im Wesentlichen zwischen den beiden Polen des Zuspruchs zu einer erzählerisch innovativen Fusion von wissenschaftlichen und literarischen Diskursen und der Kritik an einem zu konstruierten, zu belehrenden Charakter von Volpis Prosa -

12 Zur Verkäuflichkeit bzw. Konjunktur verschiedener Romane aus Lateinamerika, die sich mit dem Nationalsozialismus befassen, vgl. vor allem das erste Kapitel in Hoyos (2015: 33-64). 
nichts anderes letztlich als eine Kritik an der erzählerischen Umsetzung beim Zusammenführen verschiedener Genres und Diskurse.

Der Erfolg beim Lesepublikum war dennoch beachtlich, ganz besonders in Deutschland, wo durch die Thematik, aber auch durch die Anlehnung an traditionsreiche literarische Stoffe wie den Parzival-Mythos oder das Faust-Thema eine besondere Anschlussfähigkeit eine Rolle spielt. In der Beilage der Welt am Sonntag zur Buchmesse in Frankfurt am 07. Oktober 2001 wird Volpis Roman an zweiter Stelle auf der Liste der meistverkauften Bücher geführt (López de Abiada/ Leuenberger 2004: 365).

Mit En busca de Klingsor hat Volpi einen Roman vorgelegt, der offenbar ein spezifisches weltliterarisches Rezeptionsmuster entscheidend mitgeprägt hat. Inwiefern sich dieses als dauerhaftes Weltliteratur-Paradigma durchzusetzen vermag, bleibt abzuwarten. Mit seinen folgenden Romanen ${ }^{13}$ konnte Volpi selbst nicht mehr an den Erfolg von Klingsor anknüpfen. Die Kriterien allerdings, dass lateinamerikanische Autor/innen sich als ,westlich' geltender Themen mit innovativen erzählerischen Mitteln annehmen, dass auf verschiedenen Ebenen eines Romans wissenschaftliche Diskurse integriert werden und vor allem auch der Aspekt der Gattungsmischung lassen sich bei einer ganzen Reihe lateinamerikanischer Romane ausmachen, die in den vergangenen Jahren weltweit zirkulierten.

\section{Juan Gabriel Vásquez}

Um den Blick dafür zu schärfen, wie die Entstehungsbedingungen lateinamerikanischer Literaturen mit Fragen der Weltliteraturwerdung in der aktuellen Phase beschleunigter Globalisierung ineinandergreifen können, soll nun anhand eines dritten Beispiels - dem von Juan Gabriel Vásquez - eine weitere Dimension der Anschlussfähigkeit an etablierte literarische Traditionen gezeigt werden. ${ }^{14}$ Dabei ist nicht zuletzt die Frage bedeutsam, in welcher Weise heute explizit weltliterarische Konzepte das Schaffen selbst, die unmittelbare Arbeit von Autor/innen beeinflussen können.

13 In Paris schrieb Volpi El fin de la locura (2003), einen Roman über das Verhältnis zwischen Intellektuellen und Macht zu Zeiten der Pariser Studentenproteste im Mai 1968. No será la Tierra (2006), ein Roman über den Zerfall des Sowjetsystems 1989, bildet gemeinsam mit En busca de Klingsor und El fin de la locura Volpis Trilogie des 20. Jahrhunderts, die drei historische Großereignisse behandelt: den Zweiten Weltkrieg, die 1968er-Bewegung in Paris und den Zerfall des Sowjetsystems (Regalado López 2013: 97-103). Seit 2006 folgten noch acht weitere Romane in wechselnden Verlagen, deren letzter, Una novela criminal über den Fall Florence Cassez, 2018 mit dem Premio Alfaguara ausgezeichnet wurde (AFP 2018).

14 Die folgenden Überlegungen zu Juan Gabriel Vásquez beruhen auf meinem Artikel „Juan Gabriel Vásquez: ¿representante de una nueva literatura mundial?“ (Müller 2017c). 
Mitte der 1990er Jahre ging der kolumbianische Schriftsteller Juan Gabriel Vásquez für mehrere Jahre nach Europa: zuerst nach Paris, dann in die belgische Abgeschiedenheit der Ardennen und später nach Barcelona; mittlerweile lebt er wieder in Bogotá (Vervaeke 2013: 279). Diese im weitesten Sinne dem Nomadendasein verschriebene Lebensepoche war für seine künstlerische Entwicklung prägend und hat - wie man aus mehreren Interviews und Schriften weiß - ganz eigenen Einfluss auf sein Werk genommen, das seit der Übersetzung von Los informantes (2004) ins Englische und Französische im Jahr 2008 international rezipiert wird.

So kommt es nicht von ungefähr, dass Vásquez während seiner Jahre in Europa zwei der Weltzentren des literarischen Schaffens sowie des literarischen Betriebs ansteuerte: Paris und Barcelona, die in gewisser Weise ihren Topos als literarische Hauptstädte für lateinamerikanische Autor/innen über die letzten zwei Jahrhunderte hinweg behaupten konnten. Paris bleibt für Vásquez der „ombligo del mundo literario“ (De Maeseneer/Vervaeke 2010), so der kolumbianische Autor in einem Interview. Genauso jedoch, und dies betont Vásquez ebenfalls, sei es ein Ort, an dem diverse, und nicht nur französischsprachige Werke des Weltliteraturkanons entstanden sind.

Juan Gabriel Vásquez hat also seine Heimat verlassen und ist nach Paris gegangen, nicht (nur) um den Großen der Weltliteratur zu folgen und ihren Wegen nachzuspüren, sondern auch um zu prüfen, inwiefern ein - in seinem Falle freiwilliger - Ortswechsel sein Schreiben, seine Weltsicht, seine literarische Technik, seine Sujets und Inhalte, seine Lektüren und letztlich sein Verständnis der kolumbianischen und auch lateinamerikanischen Heimat $\mathrm{zu}$ beeinflussen und $\mathrm{zu}$ ändern vermag. ${ }^{15}$ Der Ortswechsel fungiert bei Vásquez als experimentelle Form eines Paradigmenwechsels, der in seiner weltliterarischen Tragweite auf drei Ebenen virulent ist: Auf poetologischer Ebene zeigt er sich in Denkansätzen für eine universale ,Literatur ohne festen Wohnsitz‘, auf Textebene sind es die zahlreichen impliziten wie expliziten intertextuellen Verweise, die in diese Richtung deuten, und auf der ästhetischen Ebene schließlich offenbart sich der weltliterarisch intendierte Konnex zu Gabriel García Márquez - als Kolumbianer und Lateinamerikaner. Von Vázquez selbst existieren interessante Statements zur Ästhetik García Márquez’, die er in dem kurzen Essay „Malentendidos alrededor de García Márquez“ (2005) formuliert und sich damit selbst in die weltliterarische Reflexion eingeschaltet hat.

15 Wichtige Recherchen im Zusammenhang mit Juan Gabriel Vásquez verdanke ich Sylvester Bubel. 
In einem Interview mit Rita De Maeseneer und Jasper Vervaeke aus dem Jahr 2010 gibt Juan Gabriel Vásquez zu Protokoll, dass das Abfassen großer Literatur im Ausland als expatriado wohl zur Identität des lateinamerikanischen Autors und Intellektuellen gehöre und keinesfalls etwas genuin Neues der zeitgenössischen Literatur darstelle:

Desde luego es algo que no hemos inventado ni yo ni mi generación, ni tampoco los del boom, que eran todos novelistas expatriados: Cortázar, García Márquez, Vargas Llosa y Fuentes escribieron sus grandes novelas fuera de sus países. Parece estar en la raíz de una cierta metafísica del escritor latinoamericano. (De Maeseneer/Vervaeke 2010)

Wenn Vásquez von einer Metaphysik des Schreibens außerhalb des ,Mutterlandes' spricht und dadurch gar ein vereinendes Muster zu erkennen vermag unter den unbezweifelbaren Weltliteraten Lateinamerikas Cortázar, García Márquez, Vargas Llosa und Fuentes, vertritt er eine These, die besagt, dass so etwas wie Literatur, die Chancen haben könnte, in den Kanon der Weltliteratur aufgenommen zu werden, erst durch Distanzierung, durch einen Akt der Selbstbefreiung aus der Gewohnheit, dem Bekannten und Vertrauten erzielt werden kann. Dazu gehört auch, die angestammten, anerlernten, liebgewonnenen, aber auch begrenzenden Denkmuster und Haltungen hinter sich zu lassen: „Establecer una distancia con el lugar de donde viene, con el hogar“ (De Maeseneer/Vervaeke 2010) - dies war also der Impetus für seine eigene Auswanderung. Paris, „lugar de acogida de varias literaturas“ (ebd.), habe ihm, nicht zuletzt durch die Tradition und auch Dichte des literarischen Betriebes, auch technische und damit poetologische Fragen beantwortet und avancierte so zu einem Teil seiner eigenen „mitología personal“ (ebd.), den er mit so vielen internationalen und lateinamerikanischen Autor/innen teilt: „Mi idea era que estando fuera de mi país la escritura se haría realidad con menos resistencias y mayores elementos de juicio, y aprovechando una mayor contaminación“ (ebd.), so lässt sich Vásquez weiter in dem Interview zitieren, und er möchte sein Leben außerhalb der Heimat keineswegs als eine Form der Diaspora bezeichnet wissen, da in diesem Terminus immer „cierta pretensión de superioridad moral“ (Vásquez 2009: 179) mitschwinge. Auch der Begriff des Exils erscheint Vásquez nicht adäquat, sei er doch konnotiert mit einem „prestigio curioso“ sowie einem durch die politischen und kriegerischen Entwicklungen des 20. Jahrhunderts immer mitschwingenden „color político“(ebd.).

Für sich selbst, der jederzeit problemlos und restriktionsfrei in sein Herkunftsland hätte zurückkehren können, hat Vásquez den Begriff des inquilino gewählt, ${ }^{16}$

16 Der Begriff des inquilino verdankt sich Vásquez’ Beschäftigung mit V.S. Naipaul, der von einem Kritiker so genannt wurde (vgl. Vásquez 2009: 179). 
um seine eigene Situation in Analogie zur Tierwelt zu beschreiben: „inquilino es cualquier animal que vive en la madriguera o el nido de un animal de otra especie“ (Vásquez 2009: 179). Besonders das Gefühl, als inquilino unterwegs, auf der Durchreise zu sein („estar de paso“), gefällt ihm - und ihm scheint dieser Lebenswandel, genauer gesagt der Impetus, freiwillig in die Fremde zu streben, eine Parallele mit dem Leseakt zu haben:

\begin{abstract}
Desde 1996 me he ido de tres países distintos, y cada vez me parece más probable que las razones que uno tiene para vivir en lugares ajenos se acaben pareciendo a las que tiene para leer ficción de la buena: ampliar nuestra noción, insoportablemente confinada y estrecha y miope y provinciana, de la experiencia humana, de lo que es y no es la experiencia humana. Sólo hay otro motivo para leer buena ficción, y es ampliar nuestra noción de lo que es la buena ficción. Y eso se puede hacer - por lo menos en teoría - sin ir a meterse entre animales de otra especie. (Vásquez 2009: 180)
\end{abstract}

Vásquez sieht sich durch seine Haltung jedoch mit einem gängigen Vorurteil unter Literat/innen konfrontiert (personifiziert und formuliert durch Philip Roth), eben der Frage, wie ein ,entwurzelter' Autor sein Thema finden kann, wenn er nicht im eigenen Land lebt; und es ist Vásquez’ Anliegen, dieser „tradición faulkneriana que considera que la única manera de ser universal es ser rabiosamente local“ entgegenzutreten und die Frage zu stellen: „Qué implica, para un novelista y para su obra, estar en el extranjero mientras esa obra se construye, qué implica el desarraigo?“ (Vásquez 2009: 180). Eine Antwort auf diese Frage ist für Vásquez die Hybridisierung, die ein solches literarisches Schaffen im Ausland erfährt: „Escribir fuera, igual que leer en otras lenguas, es someterse voluntariamente a la hibridación, a la impureza“ (Vásquez 2009: 184). Und es sind seiner Ansicht nach gerade die Autoren des Boom, die es geschafft hätten, die spanische Sprache ein Stück weit zu zerstören, sie neu zu entwickeln sowie typisierte Sujets ad acta zu legen, was ein großes Erbe darstelle:

Esto, entre otras cosas, nos dejaron como legado los novelistas del boom latinoamericano: el derecho a romper la lengua española, a repudiar las prosas castizas y a abrazar los barbarismos. Rayuela, Terra Nostra, Tres tristes tigres son lugares donde la lengua española de un Ciro Alegría, en Latinoamérica, o de un Azorín en España, sirve apenas dar constancia. (Vásquez 2009: 184)

Es ist also eine neue Sprache, die der Boom mitgeschaffen hat, eine Sprache, „del carácter itinerante, desarraigado, multilingüe y contaminado“, deren sich der escritor inquilino auch zu bedienen habe, um nicht wie ein „notario“ zu klingen (Vásquez 2009: 184, 186).

Wie sieht nun die Themenwahl des escritor inquilino aus? Dieser möchte, so Vásquez, das Unbekannte erforschen, er möchte, und hier bezieht er sich wie 
schon beim Begriff des inquilino wieder auf Naipaul, „revivir el asombro del lector ante un mundo que es, por derecho propio, asombroso“ (Vásquez 2009: 186) und eine der wichtigsten Tugenden bei dieser Exploration des Verschütteten beziehungsweise Wiederbelebung des Staunens ist die topisch besetzte Suche (el buscar). Die Parallele zu Jorge Volpi, dessen Roman En busca de Klingsor die Suche bereits im Titel trägt - wenn auch unter anderen Vorzeichen -, drängt sich an dieser Stelle auf und wäre sicher einer näheren Untersuchung würdig. Vásquez selbst wehrt sich vehement gegen Forschung und Kritik, die wiederholt ein solch „inquisitives Erforschen“ („la condición exploradora o inquisidora de la novela“; Vásquez 2009: 187) eines geographischen Raumes oder einer bestimmten Epoche im Roman für ein Schreiben in Kolumbien nach dem gigantischen Werk von Gabriel García Márquez negiert hat. Niemals sei die Suche nach und Entdeckung von Geschichte(n) und Sujets eines Raumes ,aufgebraucht‘ oder abgeschlossen.

Doch erst sein persönlicher Werdegang, seine Reise durch Europa sowie seine breite Lektüre und Beschäftigung mit Weltliteraten wie Joseph Conrad und V.S. Naipaul haben Vásquez dahin geführt, in Los informantes (2004) über seine Heimat Kolumbien zu schreiben; gerade wegen der „condición de zona oscura“ (Vásquez 2009: 187), die das Land für ihn darstellt, ist es zum wichtigen, wenn nicht zum zentralen Sujet seiner Romane geworden: „hoy, en cambio, la falta de certezas me parece la mejor razón para emprender el complejo aparato preguntón que es una novela“ (Vásquez 2009: 188). Insbesondere die Anspielungen auf weltliterarische Sujets in Los informantes fügen sich dabei nahtlos in die Konzeption eines solchen Kolumbien-Romans ein. In Los informantes wird erzählt, dass der Protagonist Gabriel Santoro der Ältere, ein Rhetorikprofessor in Bogotá, während seiner Adoleszenz ein Verbrechen begangen hat: Fälschlich und mutwillig denunziert er während des Zweiten Weltkrieges den deutschstämmigen Konrad Deresser, Vater seines besten Freundes Enrique, wodurch dieser auf die sogenannte ,schwarze Liste“ der USA kommt, interniert wird, sein geschäftliches wie privates Leben zerstört sieht und sich dann in der Konsequenz durch einen „coctel de aguardiente y pólvora“ (Vásquez 2004: 119) selbst tötet. Enrique verschwindet nach dem Tod seines Vaters. Aus Rache lässt er seinem ehemaligen Freund Gabriel Santoro auflauern: Bei einem Machetenangriff durch Unbekannte verliert dieser mehrere Finger. Auch um sich seine erfolgreiche Karriere nicht $\mathrm{zu}$ verbauen, versucht Gabriel jahrzehntelang, seine Tat $\mathrm{zu}$ vertuschen, bis sein gleichnamiger Sohn sie schließlich aufdeckt und dann, nach dem Unfalltod des Vaters Anfang der 1990er Jahre, ein Buch mit dem Namen Los informantes schreibt.

Dem Roman stellt Vásquez prominent zwei Zitate von Demosthenes voran und in der Chronologie des Lesens stößt man zunächst auf diese beiden Motti im Paratext, die wichtige Essenzen des Inhaltes präfigurieren. Das erste lautet: 
„Nunca te purificarás tú de las acciones por ti mismo allí realizadas; no hablarás tanto como para eso“; anschließend sind drei Fragen zu lesen: „¿Quién quiere hablar? ¿Quién quiere hacer acusaciones respecto de los acontecimientos pasados? ¿Quién quiere garantizar el porvenir?“ (Vásquez 2004: 9). Beide Zitate stammen aus der so bekannten Kranzrede (Sobre la corona) von Demosthenes, zu dem im Roman immer wieder Bezüge hergestellt werden. Dass Vásquez gerade den wohl wichtigsten Redner der Antike als Anwalt beziehungsweise Symbol für die Allgegenwärtigkeit der nationalsozialistischen Schrecken in der kolumbianischen Peripherie voranstellt, verdeutlicht den von ihm in seiner Poetik postulierten Grundsatz, dass seine „experiencia extraterritorial“ (Vásquez 2009: 188) sowie seine universelle Beschäftigung mit Literatur den kolumbianischen Komplex im Roman bereichert hat.

In dem erwähnten Essay „Malentendidos alrededor de García Márquez“ aus dem Jahr 2005 äußert sich Juan Gabriel Vásquez zu García Márquez als Referenzpunkt für sein Schreiben:

¿Cómo se escribe bajo la sombra de Cien años de soledad? La pregunta me parece un falso problema, casi una vacuidad retórica, y lo he dicho más de una vez en más de una entrevista. Pero hoy intentaré dar a mis reparos un empaque menos indignado y más racional, menos informal y más articulado. (Vásquez 2005: 42)

Dieser Konnex ist wohl weniger einer kolumbianischen Verbundenheit der beiden Autoren geschuldet, als vielmehr der weltliterarischen Unhinterfragbarkeit des Nobelpreisträgers, der hier stellvertretend für die lateinamerikanische BoomGeneration stehen mag. Die weltweite Durchsetzungskraft von García Márquez' emblematischem Roman Cien años de soledad hängt eng mit zwei tragenden Säulen zusammen, die fundamental für den Erfolg des Boom waren: innerliterarisch die erfolgreiche Inszenierung des Projekts einer spezifisch lateinamerikanischen Identitätssuche, gepaart mit einer formalen Dimension, die es erlaubt, den Roman als Epos zu lesen; außerliterarisch eine erstmalige Unabhängigkeit des lateinamerikanischen Autors vom Regierungssystem, gepaart mit einer linksgerichteten Parteinahme im Sartre'schen Sinne, d.h. als Sprachrohr für das unterdrückte Volk. Konkret bedeutet dies, dass sich innertextuell einerseits ein Ringen um Identität zeigt, bevorzugt im Rekurs auf mythische Elemente wie einem zyklischen Zeitverständnis oder speziellen Motiven, wie dem der Maske. Diese Elemente wollen eine kollektive Identität begründen, die das Autochthone, Präkolumbische betont und sich dadurch von der europäischen Hegemonie befreit. Dieser emanzipative Versuch wird durch die formale Inszenierung der inhaltlichen Aspekte noch potenziert, und zwar insofern, als die genannten Motive in novelas totales und utopische Entwürfe integriert sind. Die Verbindung von formaler Totalität und identitätsstiftendem Moment erlaubt es, Cien años de soledad 
als Epos zu lesen. Die weltliterarische Überzeugungskraft dieses Romans (wie auch anderer Boom-Romane) liegt also im Projekt, d.h. in einer spezifisch lateinamerikanischen Identität, die über den Rückgriff auf eine kulturelle Essenz (Ursprung) gesucht wird.

Zudem wird bei García Márquez, wie im ersten Teil dieses Kapitels dargestellt wurde, stellvertretend für die gesamte lateinamerikanische Literatur Ende der 1960er Jahre eine Entwicklung abgeschlossen, die in Westeuropa bereits zur Jahrhundertwende ihren Höhepunkt erreicht hat mit dem, was Pierre Bourdieu die Autonomie des literarischen Feldes nennt. Die Folgeentwicklung jüngerer Generationen lateinamerikanischer Autor/innen - und in diesem Fall von Juan Gabriel Vásquez - hängt in nicht unwesentlichem Maße mit jener erreichten Autonomie der Boom-Generation zu diesem Zeitpunkt (Ende der 1960er Jahre) zusammen.

Vor dieser historischen Folie lässt sich die weltliterarische Bedeutung des Vásquez'schen Werkes neu verorten und zudem mit ihm eine neue Entwicklung lateinamerikanischer Literaturen im Rahmen weltliterarischer Selektionsprozesse ausmachen. Die Suche nach einer spezifisch lateinamerikanischen Identität scheint nicht mehr der dominante Rezeptionsfilter zu sein. Vásquez’ Romane zeigen sich weniger utopieversessen, weniger ideologisch entschieden, weniger hochkulturell. Dafür kommen das Spielerische, das Parodistische, die Mischung von Hoch- und Alltagskultur, das Geschichtliche stärker zum Ausdruck. Im Gegensatz zum gesellschaftskritischen, utopischen Potential von einst ist die politische Dimension bei ihm weniger tendenziös.

Während in lateinamerikanischen Literaturen mit dem Prädikat Weltliteratur in den 1960er Jahren eine lateinamerikanische Kultur, die sich (diachron) aus ihren Wurzeln nährt, als kohärent von innen gezeigt wurde und eine unmittelbare Gegenüberstellung mit dem gleichzeitigen kulturell Anderen, v.a. Europa und Nordamerika, ausblieb, so thematisiert Vásquez Identität heute als individuelle Entwicklung, die sich erst in der (synchronen) Konfrontation mit dem Anderen abzeichnet. Von all seinen Romanen vermittelt El ruido de las cosas al caer am intensivsten ein alternatives Identitätsmodell $\mathrm{zu}$ dem eines García Márquez oder der Boom-Romane überhaupt. Die Erinnerung an eine spezifische Periode in der kolumbianischen Geschichte - die 1980er und vor allem 1990er Jahre als post-violencia-Phase - ermöglicht eine kollektive Leseerfahrung, die ihre Originalität einer Überlappung zweier Phänomene verdankt. Dies ist zunächst eine für außerkolumbianische Leser durchaus exotistische Inszenierung des Lebens mit dem Phänomen des narcotráfico, die innerhalb der kolumbianischen Leserschaft als identitätsstiftendes Band wirkt. Dieses Band eines zunächst nationalen Rezeptionsrahmens wird aber durch Ironie und Anekdotenhaftigkeit gesprengt und damit anschlussfähig an international etablierte weltliterarische Lektüremuster. 
Das Wachrufen einer kollektiven Erinnerung an eine präkolumbische Vergangenheit in Cien años de soledad wird ersetzt durch einen recht aktuellen Erinnerungsdiskurs, den der 1980er und 1990er Jahre:

La gente de mi generación hace estas cosas: nos preguntamos cómo eran nuestras vidas al momento de aquellos sucesos, casi todos ocurridos durante los años ochenta, que las definieron o las desviaron sin que pudiéramos siquiera darnos cuenta de lo que nos estaba sucediendo. (Vásquez 2011: 227)

[...] Maya volvió a recordar, volvió a dedicarse al fatigoso oficio de la memoria. (Vásquez 2011: 244)

Damit wird ein alter durch einen neuen Exotismus abgelöst, der durch innertextuelle Dimensionen eine weltliterarische Durchsetzungskraft erlangt. 